\title{
PRODUÇÃO DO TOMATE CEREJA EM AMBIENTE PROTEGIDO SOB INFLUÊNCIA DA LÂMINA DE IRRIGAÇÃO E ADUBAÇÃO ORGÂNICA
}

\section{CHERRY TOMATO PRODUCTION IN A PROTECTED ENVIRONMENT UNDER THE INFLUENCE OF IRRIGATION LAMINA AND ORGANIC}

\author{
Aline Daniele Lucena de Melo Medeiros ${ }^{1}$; Liherberton Ferreira dos Santos ${ }^{2}$; Silvanete \\ Severino da Silva ${ }^{3}$ Rutilene Rodrigues da Cunha ${ }^{4}$; Roberto Vieira Pordeus ${ }^{5}$
}

DOI: https://doi.org/10.31692/978-65-991061-7-0.191-201

\begin{abstract}
RESUMO
O objetivo desse estudo foi avaliar os aspectos morfológicos do tomate cereja na região oeste do estado do Rio Grande do Norte sob diferentes níveis de reposição hídrica e dosagens de adubação orgânica. $\mathrm{O}$ experimento foi conduzido, em casa de vegetação, cultivado em vasos plásticos de $10 \mathrm{~L}$, na Universidade Federal Rural do Semi-Árido-UFERSA, no município de Mossoró/RN. Os tratamentos consistem na combinação fatorial $5 \times 3$, cinco lâminas de água: $\mathrm{L} 1=70 \%, \mathrm{~L} 2=80 \%, \mathrm{~L} 3=90 \%, \mathrm{~L} 4=100 \%$ e $\mathrm{L} 5=120 \%$ da $\mathrm{ET}_{0}$ e três dosagens de adubação orgânica: $\mathrm{T} 1=$ solo $+10 \%$ de Bio Adubo, $\mathrm{T} 2=$ solo $+20 \%$ de Bio Adubo e T3 $=$ testemunha (sem adubação). A produção da cultura foi analisada através das seguintes variáveis: Número de Flores por Planta $\left(\mathrm{NF}_{\mathrm{L}} \mathrm{P}\right)$, Número de Cachos por Planta $(\mathrm{NCP})$, Número de Fruto por Planta $\left(\mathrm{NF}_{\mathrm{R}} \mathrm{P}\right)$ e Peso Total de Frutos por Planta (PTFP) em gramas. Os dados coletados foram submetidos à análise de variância pelo teste $\mathrm{F}$ e, quando significativo, feito à análise de regressão ao nível de $5 \%$ de probabilidade. De um modo geral, observou-se que a incorporação da adubação na cultura do tomate cereja contribuiu de forma eficiente para produção em todas as fases do ciclo. A produção do tomate cereja de forma geral, não é influenciado pela interação entre os fatores lâmina de irrigação e dosagem de matéria orgânica, exceto para o número de cacho por planta. O tomate cereja também é influenciado diretamente pela dosagem de matéria orgânica, independentemente da lâmina de irrigação.
\end{abstract}

Palavras-Chave: Manejo de irrigação, Produtividade, Tomateiro

\begin{abstract}
The aim of this study was to evaluate the morphological aspects of cherry tomatoes in West region of the Rio Grande do Norte state in different hydric replacement levels and dosages of organic fertilization. The experiment was conducted in a greenhouse, cultivated in plastic pails of $10 \mathrm{~L}$, at the Federal Rural University of the Semiarid - UFERSA, in the city of Mossoró. The treatments consists in $5 \times 3$ factorial combination, five water laminas: $\mathrm{L} 1=70 \%$, $\mathrm{L} 2=80 \%, \mathrm{~L} 3=90 \%, \mathrm{~L} 4=100 \%$ and $\mathrm{L} 5=120 \%$ of $\mathrm{ET}_{0}$ and three dosages of organic fertilization: $\mathrm{T} 1=$ soil $+10 \%$ of Bio Fertilizer, $\mathrm{T} 2=$ soil $+20 \%$ of Bio Fertilizer and $\mathrm{T} 3=$ attestant (without fertilization). The production of culture was analyzed using the following variables: Number of Flowers per Plant (NFLP), Number of Clusters per Plant (NCP), Number of Fruit per Plant (NFRP) and Total Weight of Fruits per Plant (TWFP) in grams.

\footnotetext{
${ }^{1}$ Graduanda em Engenharia Agrícola e Ambiental, Universidade Federal Rural do Semi-Árido-UFERSA, alinemedeirosengenharia@gmail.com

2 Graduando em Engenharia Agrícola e Ambiental, Universidade Federal Rural do Semi-Árido-UFERSA, liherberton@gmail.com

3 Doutoranda em Engenharia Agrícola, Universidade Federal de Campina Grande-UFCG, silvanete.h@hotmail.com

4 Doutoranda em Manejo de Solo e Água, Universidade Federal Rural do Semi-Árido-UFERSA, rutilene10@hotmail.com

${ }^{5}$ Engenheiro Agrícola, Doutor em Recursos Naturais, Professor Associado, UFERSA, rpordeus@ufersa.edu.br
} 
The collected data were subjected to analysis of variance by $\mathrm{F}$ test and, when significant, it was done regression analysis at 5\% probability. In general, it was observed that the incorporation of fertilization on culture of cherry tomato contribute, efficiently, to production at all stages of the cycle. The production of cherry tomatoes in general is not influenced by the interaction between the factors irrigation blade and organic matter dosage, except for the number of bunch per plant. The cherry tomato is also influenced directly by the dosage of organic matter, regardless of the irrigation blade.

Keywords: Irrigation management, Productivity, Tomato

\section{INTRODUÇÃO}

Dentre as hortaliças produzidas no Brasil o tomate ocupa a segunda posição, tanto no aspecto econômico quanto social, o mesmo originou-se na zona andina da América do Sul, limitado ao norte pelo Equador, ao sul pelo Chile, ao oeste pelo Oceano Pacífico e a leste pela Cordilheira dos Andes, sendo domesticado no México por tribos indígenas primitivas que habitavam a região e levado para Europa no ano de 1544 (HOLCMAN, 2009).

Segundo os autores, Azevedo Filho \& Melo (2001), o tomateiro do tipo cereja tem se tornado uma alternativa para grande parte dos agricultores, uma vez que possui boa rusticidade, tolerância a pragas e doenças, alto valor de mercado, maior produtividade e boa aceitação por parte dos consumidores. Silva et al. (2011), faz menção a produção de tomate através do sistema orgânico como uma forma de agregar valor ao produto e ingressar em um mercado cuja oferta é inferior à demanda na maior parte do Brasil, tornando-se um sistema de suma importância para o país, o qual visa vários parâmetros tanto em termos econômico, social e principalmente ambiental.

O Rio Grande do Norte, apesar de dispor de condições climáticas adequadas, não alcançou, ainda, produção suficiente para evitar a importação de outros estados. Os estados em destaque para a cultura do tomate cereja no Brasil são: Bahia, Pernambuco e Ceará, que no ano de 2008, foram responsáveis por $90 \%$ da produção nesta região (IBGE, 2010).

Silva et al. (2012), relatam que para se obter bons rendimentos e lucratividade econômica com o tomateiro é necessário que os fatores inerentes à nutrição, à genética e ao uso correto de água, estejam em níveis adequados. Dentre esses fatores a utilização correta da irrigação de forma a manejar eficientemente a água para as culturas é essencial, para o desenvolvimento da produção de forma econômica e propiciar a conservação do meio ambiente.

Em virtude do que foi mencionado, é notório a importância de estudos que viabilizem a demanda hídrica da cultura do tomate cereja, a fim de uma maior rentabilidade econômica em produção e desenvolvimento sob diferentes níveis de reposição hídrica, bem como diferentes dosagens de adubação orgânica. 


\section{FUNDAMENTAÇÃO TEÓRICA}

A adubação é uma das principais tecnologias empregadas, com a finalidade de maximizar a desenvolvimento e rentabilidade das culturas, ainda que seja dispendioso para o custo inicial. Entretanto, o tomateiro é considerado, dentre as hortaliças, uma das espécies mais exigentes em adubação. Tal fator dar-se devido a cultivar apresenta baixa eficiência na absorção de nutrientes (MELO e SILVA, 2012).

Os resultados de pesquisas e as indicações técnicas para o uso da adubação orgânica é uma forma de agregar valor ao produto, garantindo quantidade e qualidade para ingressar em um mercado cuja oferta é muito inferior à demanda na maior parte do Brasil (SOLINO et al., 2010; MARTÍNEZ BLANCO et al., 2009). Porém, existe consenso de que dentre os materiais utilizados na adubação orgânica, o húmus de minhoca se sobressai por ser uma alternativa de incremento de qualidade, no sistema de produção orgânico (OLIVEIRA et al., 2013). Este húmus, é rico em micro e macros nutrientes entre eles estão: nitrogênio, fósforo, cálcio, potássio, magnésio e enxofre, garantindo os aspectos físicos, químicos e biológicos do solo (ARAÚJO NETO et al., 2009; OLIVEIRA et al., 2013a; PEREIRA et al., 2013).

\section{METODOLOGIA}

O experimento foi conduzido em ambiente protegido, em casa de vegetação, entre os meses de agosto de 2014 a julho do ano de 2015, na Universidade Federal Rural do SemiÁrido (UFERSA), no Departamento de Ciências Ambientais e Tecnológicas (DCAT).

A UFERSA está localizada na BR 110, km 47, no município de Mossoró-RN, cujas coordenadas geográficas de latitude: $5^{\circ} 12^{\prime} 48^{\prime \prime} \mathrm{S}$; longitude: $37^{\circ} 18^{\prime} 44^{\prime \prime} \mathrm{W}$ e altitude: $37 \mathrm{~m}$ estão acima do nível do mar. A cidade de Mossoró tem clima do tipo BSWh’i, segundo a classificação climática de Koppen, considerado como quente e seco, com precipitação pluviométrica bastante irregular, média anual de $673,9 \mathrm{~mm}$; temperatura de $27^{\circ} \mathrm{C}$ e umidade relativa do ar média de 68,9\% (CARMO FILHO: OLIVEIRA, 1995).

A Casa de vegetação onde foi desenvolvida a pesquisa é do tipo capela, construída em estrutura de alvenaria e ferro, com orientação Norte-Sul, cobertura em arco, composta com filme de polietileno de baixa densidade com aditivo anti-ultravioleta e espessura de 150 micras, protegida nas laterais com malhas negra 50\%, possuindo $18 \mathrm{~m}$ de comprimento, $6,4 \mathrm{~m}$ de largura e $3 \mathrm{~m}$ de altura do pé direito, totalizando $115,2 \mathrm{~m}^{2}$, com piso de barro batido.

O solo do experimento foi coletado em uma propriedade agrícola localizada na estrada da raiz, no município de Mossoró-RN. Foram realizadas análises físico-químicas no 
Laboratório de Análise de Solo, Água e Planta - LASAP, da UFERSA, e classificado como Areia Franca, densidade de partícula do solo $2,46 \mathrm{~g} \mathrm{~cm}^{-3}$, e teor de matéria orgânica existe no solo de $14,16 \mathrm{~g} \mathrm{~kg}^{-1}$.

O delineamento experimental utilizado foi de blocos ao acaso. O ensaio consiste de uma combinação fatorial de 15 tratamentos, combinados em um arranjo de $5 \times 3$ (lâmina x adubação), analisados em um esquema de blocos casualizados (5 blocos) com cinco repetições num total de 75 plantas espaçadas em 1,0 m entre fileiras e 0,33 m entre plantas. Para a aplicação dos tratamentos foram realizadas as determinações das doses de adubação orgânica conforme as sugestões da proposta da pesquisa. As 75 plantas foram distribuídas em cinco bancadas experimentais, com capacidade para 15 plantas por bancada.

Os tratamentos foram compostos a partir da combinação dos fatores, lâmina $\mathrm{x}$ adubação, sendo cinco lâminas de água (água de abastecimento), $\left(\mathrm{L} 1=70 \% \mathrm{ET}_{0} ; \mathrm{L} 2=80 \%\right.$ $\mathrm{ET}_{0} ; \mathrm{L} 3=90 \% \mathrm{ET}_{0} ; \mathrm{L} 4=100 \% \mathrm{ET}_{0}$; e L5 $=120 \% \mathrm{ET}_{0}$ ), da evapotranspiração, obtidas através do tanque classe A, e três doses de adubação orgânica com BIO ADUBO (A1 = Adubação orgânica 10\%; A2 = Adubação orgânica 20\% e A3 = Testemunha, sem adubação).

De acordo com dados fornecidos pelo fabricante (FERTIL VIDA), o Bio Adubo é um composto que contém nutrientes orgânicos que aumentam o crescimento, o enraizamento e dá mais vigor as plantas apresentando efeito imediato. O Bio Adubo é constituído por: bagaço de cana, esterco bovino, esterco de galinha, serragem de madeira, sulfato de cálcio (gesso agrícola) e rocha fosfática.

As leituras das variáveis de produção foram obtidas aproximadamente aos 45 DAT, sendo realizadas três coletas, uma a cada quinzena, a fim de determinar a produção total da cultura, com base nas seguintes variáveis: Número de Flores Planta ${ }^{-1}\left(\mathrm{NF}_{\mathrm{L}} \mathrm{P}\right)$, mediante contagem das flores existente nos cachos em cada planta; Número de Cachos Planta $^{-1}$ (NCP) determinado a partir do surgimento da inflorescência a cada 15 dias e quantificados durante o ciclo da cultura, através do procedimento de contagem de cachos existentes por planta; Número de Frutos Planta $^{-1}\left(\mathrm{NF}_{\mathrm{R}} \mathrm{P}\right)$, obtida mediante a contagem de todos os frutos por planta. A colheita deu-se durante a fase inicial de identificação de maturação dos frutos, a partir do processo de transição da cor amarelada para a vermelha; e Peso Total de Frutos Planta ${ }^{-1}$ (PTFP) realizado após a colheita utilizando balança analítica de precisão $\pm 0,001$.

\section{RESULTADOS E DISCUSSÃO}

O Número de cacho por planta (NCP) foi influenciada pela aplicação conjunta da lâmina de irrigação e da matéria orgânica, adotados no experimento, aos 30, 60 e 90 DAT 
(Tabela 1), constatando-se efeito significativo da interação entre os fatores a $1 \%$ de probabilidade $(\mathrm{p}<0,01)$ em todos os períodos analisados, com coeficiente de variação dentro do limite aceitável. Quando se analisou separadamente a lâmina de irritação e a adubação orgânica, constatou-se significância da lâmina de irrigação somente aos 90 DAT, a 5\% de probabilidade, enquanto a analise isolada da matéria orgânica foi significativo nos três períodos analisados, ao nível de $1 \%$ de probabilidade. Quanto aos Coeficientes de Variação observou-se redução na dispersão dos dados com o crescimento dos dias após o transplantio.

Tabela 1: Resumo da análise de variância e quadrados médios para o Número de Cachos por Planta (NCP) do tomate cereja em função da lâmina de irrigação e adubação orgânica. Mossoró - RN, 2015. Fonte: Própria

\begin{tabular}{lllll}
\hline \multirow{2}{*}{\begin{tabular}{l} 
Fonte de $\begin{array}{l}\text { Quadrado médio } \\
\text { variação }\end{array}$ \\
\cline { 3 - 5 }
\end{tabular}} & GL & $\begin{array}{l}\text { Número de Cachos } \\
\text { (NCP) }\end{array}$ & por & Planta \\
\cline { 3 - 5 } & & $30 \mathrm{DAT}$ & $60 \mathrm{DAT}$ & $90 \mathrm{DAT}$ \\
\hline LI & 4 & $2,447^{\mathrm{ns}}$ & $4,267^{\mathrm{ns}}$ & $5,280^{*}$ \\
MO & 2 & $51,613^{* *}$ & $58,440^{* *}$ & $64,120^{* *}$ \\
MO x LI & 8 & $7,147^{* *}$ & $11,006^{* *}$ & $10,320^{* *}$ \\
Bloco & 4 & $5,413^{\mathrm{ns}}$ & $4,680^{\mathrm{ns}}$ & $5,647^{*}$ \\
Resíduo & 56 & 2,463 & 2,830 & 1,902 \\
\hline CV $(\%)$ & & 24,57 & 23,11 & 15,97 \\
\hline
\end{tabular}

${ }^{\text {ns }}$ não significativo pelo Teste $\mathrm{F}$; ** significativo a $1 \%$ de probabilidade pelo Teste $\mathrm{F}$; $*$ significativo a $5 \%$ de probabilidade pelo Teste $\mathrm{F}$.

Observa-se na Figura 1, que o número de cacho por planta cresceu de forma linear e polinomial, verifica-se também maior influência da matéria orgânica no mesmo. Verificou-se que aos 30 e 60 DAT, o crescimento no número de cacho por planta (NCP) se dá mais na forma linear, enquanto aos 90 DAT o comportamento do crescimento ocorre mais de forma polinomial. Na Figura 1A, verifica-se que quando se trabalhou sem adubação orgânica, o menor NCP foi obtido quando se utilizou a menor lâmina de irrigação (0,7ETo) e o maior NCP foi com a lâmina de 0,8 ETo. Já para condição máxima de adubação, não foi observado diferença significativa no NCP. Nas Figuras 1B e 1C, aos 60 e 90 DAT, para condição sem adubação o menor NCP foram obtidos para as lâminas 0,8 e 1,0ETo respectivamente, enquanto o maior NCP foi obtido para lâmina de 1,2ETo para ambos períodos, 60 e 90DAT. Já na condição máxima de adubação o menor NCP foi quando se aplicou a lâmina de irrigação com excesso (1,2ETo), em todos períodos estudados, tendo também o maior NCP quando aplicou a necessidade hídrica requerida pela planta (1,0ETo). 
Figura 1. Número de cachos por plantas do tomate cereja em função de adubação orgânica e lâmina de irrigação em diferentes fases fenológicas da cultura: Aos 30 DAT (a); 60 DAT (b); e 90 DAT (c). Mossoró - rn, 2015.

A

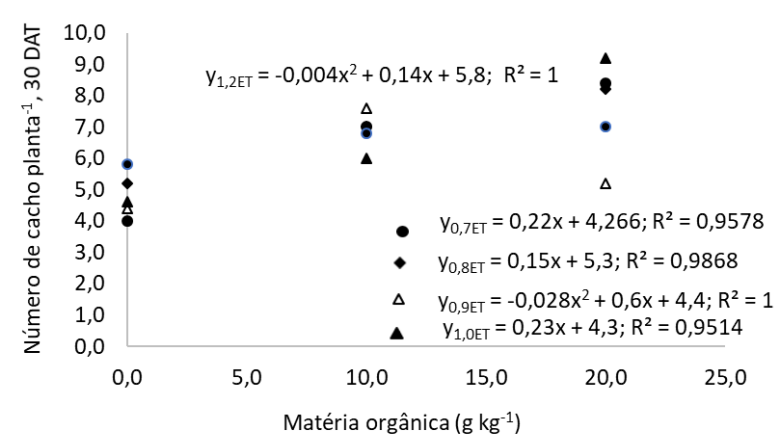

B

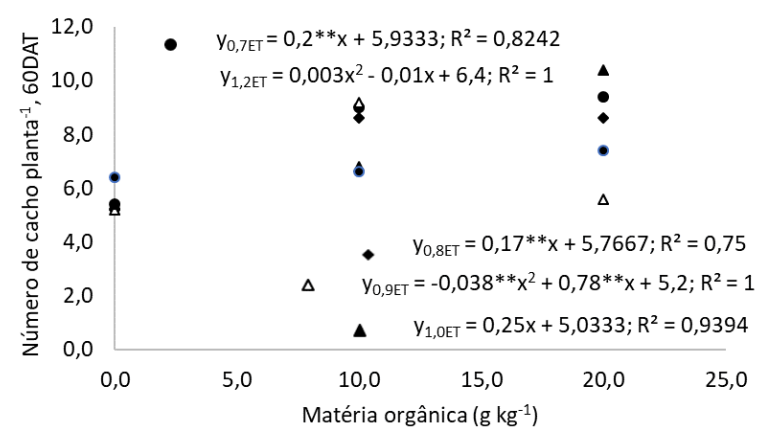

C

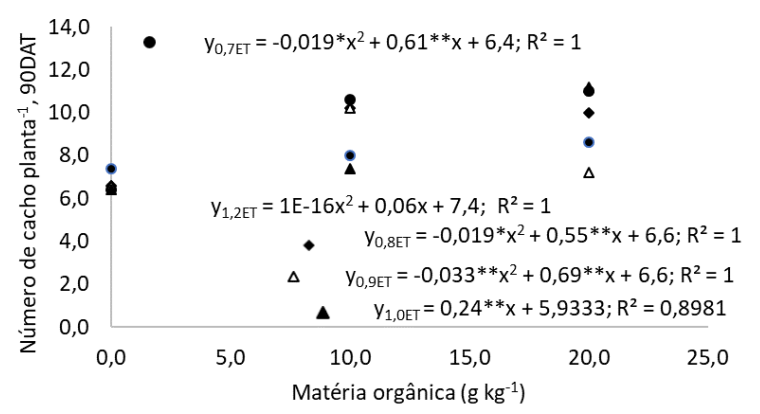

Na Tabela 2, constatou-se que quando se analisou as lâminas de irrigação, verificou-se melhor resposta do número de cacho por planta $(11,2 \mathrm{NCP})$ para aplicação da lâmina de 1,0ET, aos 90 DAT e adubação de $20 \mathrm{~g} \mathrm{~kg}^{-1}$. Enquanto o menor número de cacho obtido foi para condição sem adubação e lâmina de 0,7ET, aos 30 DAT.

Quando se fixou na Tabela 2 a lâmina de irrigação e variou-se a dosagem de adubação verificou-se crescimento no número de cacho por planta, com o aumento da dosagem de adubação. Para menor lâmina de irrigação (0,7ET) a variação no NCP foi de $110 \%$ enquanto para lâmina de 1,0ETo a variação foi de $100 \%$, no entanto, quando se trabalhou com a lâmina com excesso de irrigação (1,2ET) a adubação orgânica contribuiu de forma tímida no crescimento do número de cacho por planta $(21 \%)$. No entanto, quando se comparou as condições de déficit de irrigação em relação ao excesso, observou-se que o excesso de irrigação prejudica mais a produção, redução no número de cacho por planta, do que o déficit.

Os resultados mostraram que quando se fixou a matéria orgânica e variou-se a lâmina de irrigação, observou-se tendência de crescimento do número de cacho por planta. Verificouse também, que quando se trabalhou sem matéria orgânica a lâmina de irrigação de 1,2 ETo apresentou uma produção de $45 \%$ superior à obtida com a menor lâmina de irrigação (0,7ETo), no entanto, quando se aplicou a lâmina correspondente a 100\% de ETo, o 
crescimento foi de $15 \%$ no número de cacho por planta em relação à condição de déficit de 30\% da necessidade hídrica da planta. Já quando se aplicou a dosagem máxima de matéria orgânica, verificou-se menor variação no número de cacho por planta. Quando se comparou a lâmina de irrigação correspondente a 1,2ETo em relação a lâmina de 0,7ETo observou-se redução no NCP de $22 \%$, já quando comparou-se a produção obtida com a lâmina de 1,0ETo em relação a obtida com a lâmina de 0,7ETo teve um crescimento de apenas 2,0\% aos 90 DAT. Seleguini et al. (2006), estudando o espaçamento entre plantas e número de racimos para tomateiro em ambiente protegido constatou que a diminuição do número de cachos por planta, pode reduzir o ciclo da cultura e a altura de plantas, diminuindo o uso de mão-de-obra durante o ciclo da cultura e menor uso de defensivos agrícolas. Segundo estudos de Fontes, et al., 2006, verificou-se que o aumento do número de cachos, cresce proporcionalmente ao crescimento do caule.

Tabela 2. Análise do número de cachos por planta (NCP) do tomate cereja em relação a dosagem de adubação e lâmina de irrigação aos 30, 60 e 90 dias após o transplantio (DAT).

\begin{tabular}{ccccccccccccc}
\hline & \multicolumn{10}{c}{ Lamina de Irrigação (ETo) } \\
\cline { 2 - 14 } & \multicolumn{10}{c}{0,7} & \multicolumn{10}{c}{1,0} & & & 1,2 & \\
\cline { 2 - 13 } & 30 & 60 & 90 & 30 & 60 & 90 & 30 & 60 & 90 & 30 & 60 & 90 \\
\hline 0,0 & $\mathbf{4 , 0}$ & $\mathbf{5 , 0}$ & $\mathbf{6 , 4}$ & 5,2 & 5,2 & 6,6 & 4,6 & 5,4 & 6,4 & 5,8 & 6,4 & 7,4 \\
10,0 & 7,0 & 9,0 & 10,6 & 7,0 & 8,6 & 10,2 & 6,0 & 6,8 & 7,4 & 6,8 & 6,6 & 8,0 \\
20,0 & 8,4 & 9,4 & 11,0 & 8,3 & 8,6 & 10,0 & $\mathbf{9 , 2}$ & $\mathbf{1 0 , 4}$ & $\mathbf{1 1 , 2}$ & 7,0 & 7,4 & 8,6 \\
\hline
\end{tabular}

Laminas de irrigação: $\mathrm{L} 1=0,7 \mathrm{ETo}, \mathrm{L} 2=0,8 \mathrm{ETo}, \mathrm{L} 3=1,0 \mathrm{ETo}, \mathrm{L} 4=1,2 \mathrm{ETo}$, Matéria orgânica (MO): $\mathrm{T} 1=$ solo $+10 \%$ de Bio Adubo, $\mathrm{T} 2=$ solo $+20 \%$ de Bio Adubo e T3 $=$ testemunha (sem adubação).

Quanto ao número de flores por planta $\left(\mathrm{NF}_{\mathrm{L}} \mathrm{P}\right)$, a interação não influenciou significativamente $(\mathrm{p}>0,05)$, havendo apenas efeito isolado da matéria orgânica $(\mathrm{MO})$ aos 30 DAT e efeito isolado da lâmina de irrigação (LI) aos 90 DAT, ambos ao nível de 5\% de probabilidade $(\mathrm{p}<0,05)$. Ao analisar separadamente a lâmina de irritação e a adubação orgânica, constatou-se significância da lâmina de irrigação somente aos 90 DAT, a 5\% de probabilidade, enquanto a analise isolada da matéria orgânica foi significativo nos três períodos analisados, ao nível de $1 \%$ de probabilidade. Quanto aos Coeficientes de Variação observou-se redução na dispersão dos dados com o crescimento dos dias após o transplantio.

Tabela 2. Resumo da análise de variância e quadrados médios para o número de flores por planta $\left(\mathrm{NF}_{\mathrm{L}} \mathrm{P}\right)$ do tomate cereja em função da lâmina de irrigação e adubação orgânica. Mossoró - RN, 2015.

\begin{tabular}{|c|c|c|c|c|}
\hline \multirow{3}{*}{$\begin{array}{l}\text { Fonte de } \\
\text { variação }\end{array}$} & \multirow{3}{*}{$\mathrm{GL}$} & \multicolumn{3}{|c|}{ Quadrado médio } \\
\hline & & \multicolumn{3}{|c|}{ Número de Flores por Planta $\left(\mathrm{NF}_{\mathrm{L}} \mathrm{P}\right)$} \\
\hline & & $30 \mathrm{DAT}^{1}$ & $60 \mathrm{DAT}^{2}$ & $90 \mathrm{DAT}^{2}$ \\
\hline LI & 4 & ${ }^{1} 0,336^{\mathrm{ns}}(3.633)$ & ${ }^{2} 0,055^{\mathrm{ns}}(0,713)$ & ${ }^{2} 0,435 *(6,567)$ \\
\hline MO & 2 & ${ }^{1} 1,328 *(19.853)$ & ${ }^{2} 0,179^{\mathrm{ns}}(4,813)$ & ${ }^{2} 0,228^{\text {ns }}(4,493)$ \\
\hline MO x LI & 8 & ${ }^{1} 0,400^{\mathrm{ns}}(5.103)$ & ${ }^{2} 0,349^{\mathrm{ns}}(4,363)$ & ${ }^{2} 0,286^{\mathrm{ns}}(4,077)$ \\
\hline Bloco & 4 & ${ }^{1} 0,094^{\mathrm{ns}}(0.967)$ & ${ }^{2} 0,064^{\mathrm{ns}}(0,580)$ & ${ }^{2} 0,229^{\text {ns }}(3,400)$ \\
\hline Resíduo & 56 & $10,301(3,389)$ & ${ }^{2} 0,302(4,001)$ & ${ }^{2} 0,177(2,103)$ \\
\hline
\end{tabular}




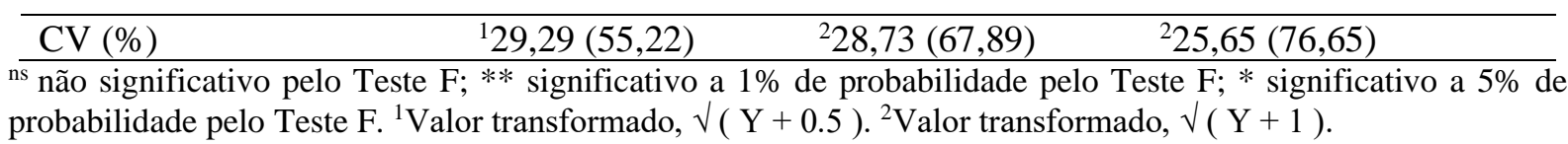

Na Figura 2, analisou-se o número de flores por planta aos 30 em função da dosagem da matéria orgânica e aos 90 DAT em função da lâmina de irrigação, observou-se crescimento polinomial aos 30 DAT, apresentando valor máximo para dosagem de 10\% de matéria orgânica, enquanto, para o período de 90 DAT ocorreu redução no número de flores com o aumento da lâmina de irrigação, esta redução provavelmente se deu devido ao crescimento da massa verde, com número de ramificação e desenvolvimento foliar.

Figura 2. Número de flores por plantas do tomate cereja em função de adubação orgânica e lâmina de irrigação em diferentes fases fenológicas da cultura: aos 30 dat (a); e 90 dat (b). Mossoró - rn, 2015

A

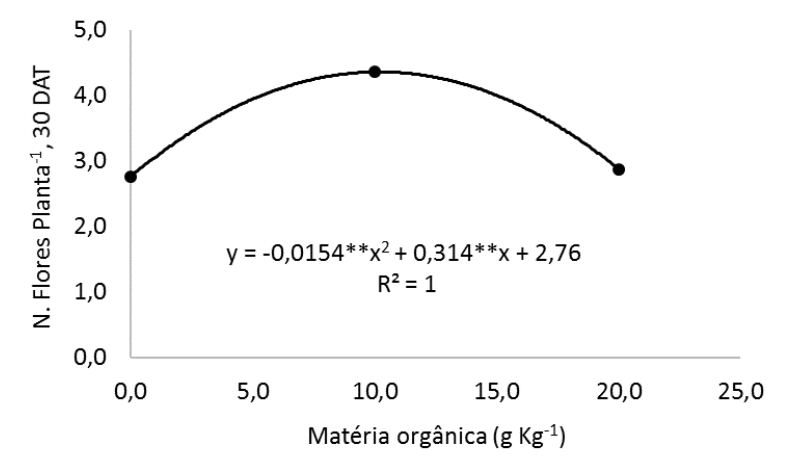

B

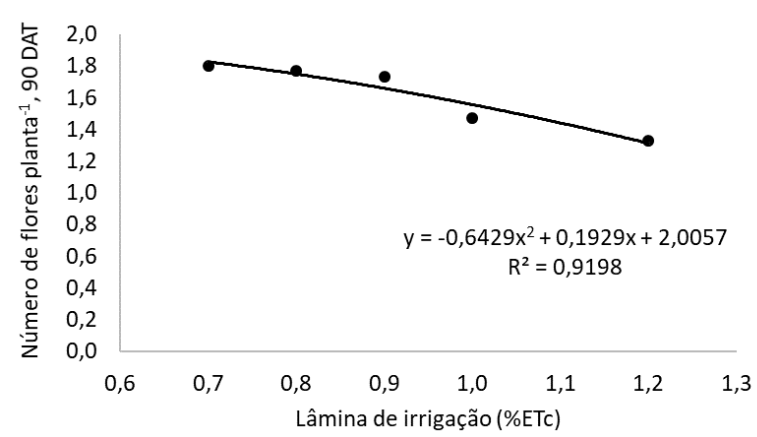

$\mathrm{O}$ Número de frutos por planta $\left(\mathrm{NF}_{\mathrm{R}} \mathrm{P}\right)$ foi afetado significativamente pela interação entre os fatores lâmina de irrigação e doses de matéria orgânica somente aos 90 DAT ao nível de $1 \%$ de probabilidade ( $<<0,01$ ). De acordo com Pulupol et al., 1996; Marouelli \& Silva, 2007, as culturas de tomateiro que são submetidas a ausência ou a grande quantidade de água, estão sujeitos ao comprometimento da produção e da qualidade dos frutos. Quando analisado isoladamente os fatores, observou-se resposta significativa ao nível de $1 \%$ de probabilidade (p $<0,01$ ) para a matéria orgânica nos três períodos analisados (Tabela 3).

Tabela 3. Resumo da análise de variância e quadrados médios para o número de frutos por planta $\left(\mathrm{NF}_{\mathrm{R}} \mathrm{P}\right)$ do tomate cereja em função da lâmina de irrigação e adubação orgânica. Mossoró - RN, 2015

\begin{tabular}{|c|c|c|c|c|}
\hline \multirow{3}{*}{$\begin{array}{l}\text { Fonte de } \\
\text { variação }\end{array}$} & \multirow{3}{*}{ GL } & \multicolumn{3}{|c|}{ Quadrado médio } \\
\hline & & \multicolumn{3}{|c|}{ Número de Frutos por Planta $\left(\mathrm{NF}_{\mathrm{R}} \mathrm{P}\right)$} \\
\hline & & $30 \mathrm{DAT}^{1}$ & $60 \mathrm{DAT}^{2}$ & $90 \mathrm{DAT}^{2}$ \\
\hline LI & 4 & ${ }^{1} 0,290^{\text {ns }}(3,620)$ & ${ }^{1} 0,460^{\mathrm{ns}}(6,813)$ & ${ }^{1} 0,200^{\mathrm{ns}}(3,567)$ \\
\hline MO & 2 & $13,714 * *(44,640)$ & ${ }^{1} 2,900 * *(36,480)$ & ${ }^{1} 1,250 * *(17,080)$ \\
\hline MO x LI & 8 & ${ }^{1} 0,290^{\mathrm{ns}}(3,340)$ & ${ }^{1} 0,259^{\text {ns }}(3,863)$ & ${ }^{1} 0,496 * *(6,347)$ \\
\hline Bloco & 4 & ${ }^{1} 0,435^{\text {ns }}(6,487)$ & ${ }^{1} 0,033^{\text {ns }}(0,913)$ & ${ }^{1} 0,102^{\text {ns }}(1,433)$ \\
\hline Resíduo & 56 & ${ }^{1} 0,311(5,558)$ & ${ }^{1} 0,253(3,585)$ & ${ }^{1} 0,157(2,066)$ \\
\hline CV (\%) & th & 136,34 & 131,20 & ${ }^{1} 28,08$ \\
\hline
\end{tabular}


Quando se analisou o número de frutos por planta (Figura 3) em relação a matéria orgânica, aos 30 e 60 DAT, verificou-se crescimento de forma linear para ambos períodos. Comparando os períodos, observou-se pequena variação no número de frutos nos períodos citados. De acordo com Silva Júnior, (2012), o efeito dos níveis de irrigação contribuiu para redução no número de frutos. De acordo com Monte et al., (2009), avaliando o manejo de irrigação em tomate para a região de Seropédica/RJ, observaram que a redução no fornecimento de água às plantas favoreceu a redução no número de frutos e, também, no tamanho desses frutos.

Figura 3. Número de frutos por plantas do tomate cereja em função de adubação orgânica e lâmina de irrigação em diferentes fases fenológicas da cultura: aos 30 DAT (a); e 60 DAT (b). Mossoró - RN, 2015

A

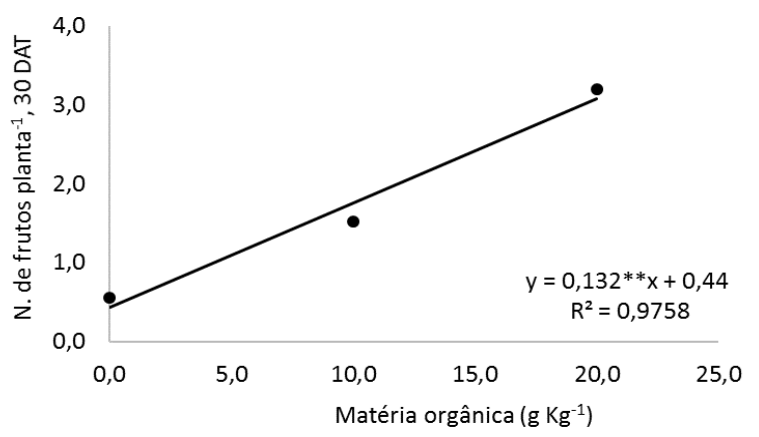

B

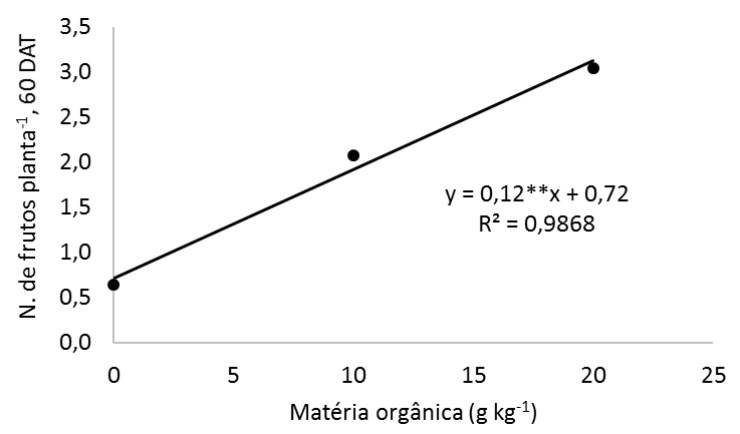

Ao analisar o peso total de frutos por planta $\left(\mathrm{PTF}_{\mathrm{R}} \mathrm{P}\right)$, constatou-se que não houve interação entre os fatores lâmina de irrigação e doses de matéria orgânica aos 30, 60 e 90 DAT, não se registrando resposta significativa quanto a interação entre estes fatores (p > 0,05). No entanto, quando analisado isoladamente os fatores aos 30 e 90 DAT, observou-se resposta significativa ao nível de $5 \%$ de probabilidade $(\mathrm{p}<0,05)$, para a matéria orgânica e lâmina de irrigação respectivamente (Tabela 4).

Tabela 4. Resumo da análise de variância e quadrados médios para o peso total de frutos por planta $\left(\mathrm{PTF} \mathrm{F}_{\mathrm{R}} \mathrm{P}\right)$ do tomate cereja em função da lâmina de irrigação e adubação orgânica. Mossoró - RN, 2015

\begin{tabular}{|c|c|c|c|c|}
\hline \multirow{3}{*}{$\begin{array}{l}\text { Fonte de } \\
\text { variação }\end{array}$} & \multirow{3}{*}{ GL } & \multicolumn{3}{|c|}{ Quadrado médio } \\
\hline & & \multicolumn{3}{|c|}{ Peso Total de Frutos por Planta $\left(\mathrm{PTF}_{\mathrm{R}} \mathrm{P}\right)$} \\
\hline & & $30 \mathrm{DAT}^{1}$ & $60 \mathrm{DAT}^{2}$ & $90 \mathrm{DAT}^{2}$ \\
\hline LI & 4 & ${ }^{1} 1,851^{\mathrm{ns}}(73,81)$ & $12,720^{\mathrm{ns}}(361,84)$ & $12,547 *(46,15)$ \\
\hline MO & 2 & ${ }^{1} 16,025^{*}(458,01)$ & ${ }^{1} 8,299^{\text {ns }}(498,70)$ & ${ }^{1} 0,320^{\mathrm{ns}}(3,67)$ \\
\hline $\begin{array}{c}\text { MO x } \\
\text { LI }\end{array}$ & 8 & ${ }^{1} 1,426^{\mathrm{ns}}(49,36)$ & ${ }^{1} 2,106^{\mathrm{ns}}(300,24)$ & ${ }^{1} 1,422^{\text {ns }}(26,41)$ \\
\hline Bloco & 4 & ${ }^{1} 2,782^{\text {ns }}(84,58)$ & ${ }^{1} 1,003^{\text {ns }}(250,78)$ & ${ }^{1} 0,423^{\mathrm{ns}}(5,38)$ \\
\hline Resíduo & 56 & ${ }^{1} 1,886(65,51)$ & $12,738(355,37)$ & ${ }^{1} 0,835(17,66)$ \\
\hline $\mathrm{CV}(\%)$ & & $157,13(115,40)$ & $1 \quad 68,02(247,80)$ & $147,10(113,36)$ \\
\hline
\end{tabular}

${ }^{\mathrm{ns}}$ não significativo pelo Teste $\mathrm{F} ; * *$ significativo a $1 \%$ de probabilidade pelo Teste $\mathrm{F} ; *$ significativo a $5 \%$ de probabilidade pelo Teste F. ${ }^{1}$ Valor transformado, $\sqrt{ }(\mathrm{Y}+1)$.

Ao analisar o peso total de frutos por planta (Figura 4), observa-se crescimento de 
forma linear em relação ao efeito isolado da matéria orgânica na lâmina de irrigação para os períodos de 30 e 60 DAT. Já para o período de 90 DAT o crescimento se deu também de forma linear em relação ao efeito isolado da lâmina de irrigação na matéria orgânica. Quando comparamos o peso dos frutos para as diferentes lâminas de irrigação, verificamos aumento de $365 \%$ no peso do fruto da lâmina máxima em relação mínima. No entanto, quando comparamos o peso dos frutos em relação a dosagem de matéria orgânica entre a máxima e a mínima dosagem aos 30 e 60 DAT, verificou-se aumento de aproximadamente $310 \%$.

Figura 4. Peso total de frutos por plantas do tomate cereja em função de adubação orgânica e lâmina de irrigação em diferentes fases fenológicas da cultura: aos 30 DAT (a), 60 DAT (b) e 90 DAT (c). Mossoró - RN, 2015

A

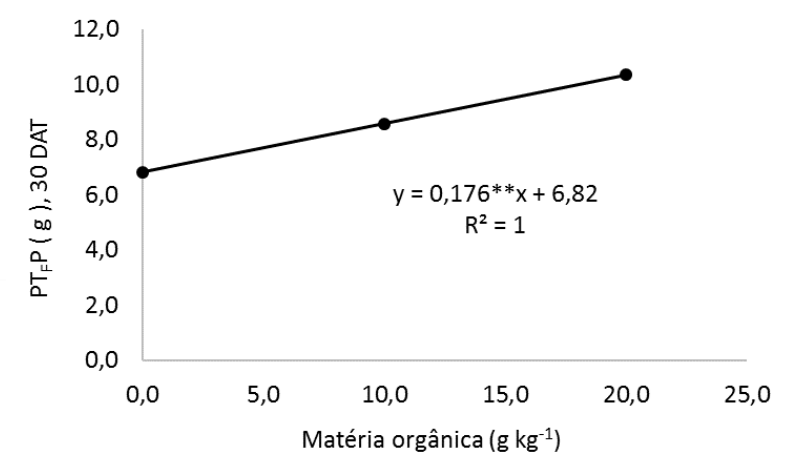

$\mathrm{B}$

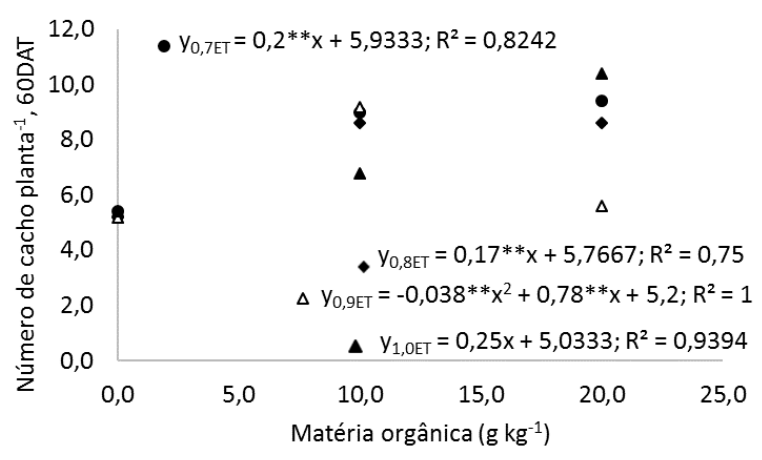

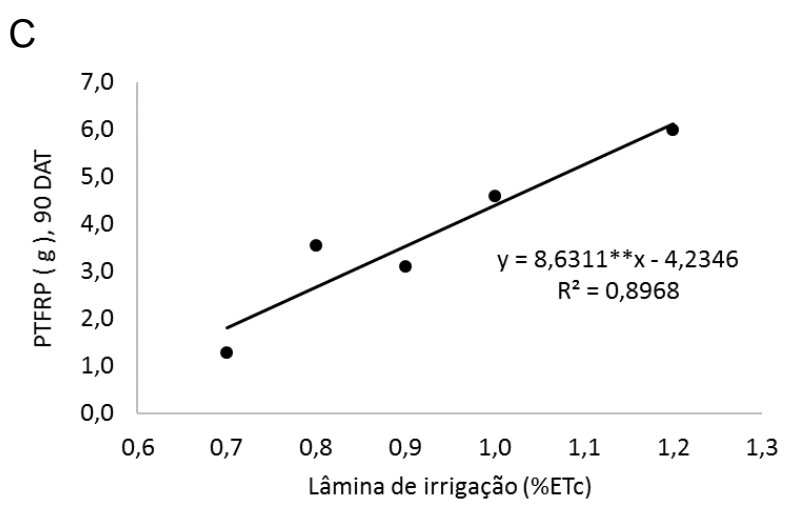

\section{CONCLUSÕES}

A produção do tomate cereja, não sofre influência da interação conjunta dos fatores lâmina de irrigação e dosagem de matéria orgânica, exceto para o número de cacho por planta. A produção de tomate cereja sofre influência direta da dosagem de matéria orgânica, independentemente da lâmina de irrigação.

\section{REFERÊNCIAS}

AZEVEDO FILHO, J. A.; MELO, A. M. T. Avaliação de tomate silvestre do tipo cereja. In: CONGRESSO BRASILEIRO DE OLERICULTURA, 41，2001，Brasília. Resumos... Brasília: ABH, 2001. CD-ROM.

CARMO FILHO, F.: OLIVEIRA, O.F. Mossoró: um município do semi-árido nordestino, caracterização climática e aspecto florístico. Mossoró: ESAN, 1995. 62p. (Coleção Mossoroense, série B). 
FONTES, P. C. R.; Ribeiro, J. M. O.; Silva, G. H. Método DFT para produção de tomate em ambiente protegido. Ciênc. Agrotec., Lavras, v. 31, n. 3, p. 713-719, maio/jun., 2007.

HOLCMAN, Ester. Microclima e produção do tomate cereja em ambientes protegidos com diferentes coberturas plásticos. 2009. 128 f. Dissertação (Mestrado) - Curso de Física do Ambiente Agrícola, Universidade de São Paulo, Piracicaba, 2009. Disponível em: <file:///C:/Users/DCAT/Downloads/Ester_Holcman (2).pdf>. Acesso em: 12 mar. 2015.

IBGE- INSTITUTO BRASILEIRO DE GEOGRAFIA E ESTATÍSTICA. Disponível em: http://www.ibge.gov.br/home/2010. Acesso em: mar. 2015.

MONTE, J. A.; PACHECO, A. S.; CARVALHO, D. F.; PIMENTEL, C. Influência do turno de rega no crescimento e produção do tomateiro no verão em Seropédica. Horticultura Brasileira, v. 27, p. 222-227, 2009.

PULUPOL L. U; BEHBOUDIAN M. H; FISHER K. J. 1996. Gowth, yield, and postharvest attributes of glasshouse tomatoes produced under deficit irrigation. HortScience 31: 926-929.

SELEGUINI A; SENO S; FARIA JÚNIOR MJA. 2006. Espaçamento entre plantas e número de racimos para tomateiro em ambiente protegido. Acta Scientiarum. Agronomy 28: 359-363.

SILVA, A. C. da; COSTA C. A. da; SAMPAIO, R. A.; MARTINS, E. R. Avaliação de linhagens de tomate cereja tolerantes ao calor sob sistema orgânico de produção. Revista Caatinga, Mossoró, v. 24, n. 3, p. 33-40, jul.-set., 2011.

SILVA, E. C. A. da; MELO, Y. de A. A viabilidade do cultivo de tomate orgânico em estufa: Um estudo de caso. 2012. 154 f. Dissertação (Mestrado) - Curso de Bacharelado em Administração, Universidade do Norte do Paraná Campus de Cornélio Procópio, cornélio procópio, 2012. Disponível em: <http://uenp.edu.br/tcc/ccp/adm/2012/06-A viabilidade do cultivo de tomate orgânico em estufa.pdf>. Acesso em: 12 mar. 2015.

SILVA JUNIOR, J. F. Desenvolvimento do tomate em diferentes níveis de irrigação e de doses de salinidade. 2013. 76 f. Dissertação (Mestrado - Curso de Agronomia, Faculdade de Ciências Agronômicas, Botucatu - SP, 2012. 